\title{
Erratum to: An ex vivo comparison of working length determination by three electronic root canal length measurement devices integrated into endodontic rotary motors
}

\author{
Manal Maree-Ali ${ }^{1} \cdot$ Ronald Wigler $^{2} \cdot$ Shaul Lin ${ }^{1,3}$ - Arieh Y. Kaufman ${ }^{1,2}$
}

Published online: 23 July 2016

(C) Springer-Verlag Berlin Heidelberg 2016

Erratum to: Clinical Oral Investigations

DOI 10.1007/s00784-016-1903-3

The original version of this article contained a mistake in the presentation of the first author name. Manal Maree Ali should have been Manal Maree-Ali.

The online version of the original article can be found at http://dx.doi. org/10.1007/s00784-016-1903-3.

Manal Maree-Ali

manalmaree@yahoo.com

1 Endodontics and Dental Traumatology Department, Graduate School of Dentistry, Rambam Health Care Campus, Haifa, Israel

2 Department of Endodontology, The Goldschleger School of Dental Medicine, Tel Aviv University, Tel Aviv, Israel

3 Rappaport Faculty of Medicine, Technion Israel Institute of Technology, Haifa, Israel 